\title{
The relation between ADHD and ANS-CNS integration
}

\author{
Maiko Hayayashida, Tsuyoshi Miyaoka, Jun Horiguchi
}

Department of Psychiatry, Faculty of Medicine, Shimane University, Izumo City, Japan

Email: maiko-s@med.shimane-u.ac.jp

Received 11 November 2013; revised 2 December 2013; accepted 9 December 2013

Copyright (C) 2014 Maiko Hayayashida et al. This is an open access article distributed under the Creative Commons Attribution License, which permits unrestricted use, distribution, and reproduction in any medium, provided the original work is properly cited. In accordance of the Creative Commons Attribution License all Copyrights (C) 2014 are reserved for SCIRP and the owner of the intellectual property Maiko Hayayashida et al. All Copyright (C) 2014 are guarded by law and by SCIRP as a guardian.

\section{ABSTRACT}

Background: Attention deficit hyperactivity disorder (ADHD) was long considered to be limited to children and adolescents, but it is now known that ADHD symptoms may persist into adulthood. It is plausible that the etiology of ADHD is not one-dimensional, but instead involves various neuroanatomical and neurochemical systems, with the causes of the main abnormalities believed to be catecholaminergic. Iodine123-labeled meta-iodobenzylguanidine $\left({ }^{123}\right.$ I-MIBG) is a physiological analogue of norepinephrine (NE). To the best of our knowledge, there are no reports about the abnormalities of MIBG scintigraphy in patients with ADHD. The cases presented are male adult patients with different comorbid psychiatric disorders. Case presentation: The cases presented are male adult patients with different psychiatric disorders. Case 1 was a 52-year-old male residential construction foreman, who had been diagnosed with acute schizophrenia-like psychotic disorder. ${ }^{123}$ I-MIBG planar and SPECTs of the studies were performed at 20 min (early phase) and $3 \mathrm{~h}$ (late phase) after intravenous injection of $111 \mathrm{MBq}$. Planar images were processed to determine the heart $(\mathrm{H})$ to mediastinum (M) ratio (H/M). The early and late $H / M$ ratios were 1.22 and 1.07, respectively. Case 2 was a 52-year-old male civil servant who was diagnosed with adjustment disorder. The early and late $\mathrm{H} / \mathrm{M}$ ratios were 1.98 and 2.08, respectively. Conclusion: Clinical studies make it clear that symptoms of ADHD are more heterogenous and subtle in adults than children. Adult ADHD is significantly commorbid with wide range of other 12-month disorders. MIBG imaging can be useful to diagnose patients with preexisting psychiatric disorders and ADHD. It might be possible to diagnose objectively though the psychiatric statuses resemble or coexist with other psychiatric disorders. Needless to say, further research is important.

\section{KEYWORDS}

Attention Deficit Hyperactivity Disorder (ADHD); Iodine-123-Labeled Meta-Iodobenzylguanidine; Single Photon Emission Computed Tomography (SPECT); Norepinephrine (NE)

\section{INTRODUCTION}

Attention deficit hyperactivity disorder (ADHD) is a complex neurobehavioral condition estimated to affect $8 \%$ to $10 \%$ of school aged children and is characterized by a symptom cluster of inattention, hyperactivity, and impulsivity (DSM-IV criteria). ADHD was long considered to be limited to children and adolescents, but it is now known that ADHD symptoms may persist into adulthood [1]. The adult ADHD is entirely a clinical one, which contributes to controversy. There is no established objective tool to diagnose. It is plausible that the etiology of ADHD is not one-dimensional, but instead involves various neuroanatomical and neurochemical systems, with the causes of the main abnormalities believed to be catecholaminergic [2].

Iodine-123-labeled meta-iodobenzylguanidine $\left({ }^{123} \mathrm{I}-\right.$ MIBG) is a physiological analogue of norepinephrine (NE). MIBG has been proven to be very useful for scintigraphic image studies of cardiac sympathetic innervations [3].

The single photon emission computed tomography (SPECT) is a useful tool for estimating local myocardial sympathetic nerve damage, not only in primary heart disease, but also in neurological disorders, with or without clinically manifested autonomic failure [3].

To the best of our knowledge, MIBG scintigraphy has not previously been used to investigate ADHD. The cases presented are male adult patients proceeded with different psychiatric disorders.

\section{METHODS}

${ }^{123}$ I-MIBG (Fujifilm RI pharma, Tokyo, Japan) was used 
for evaluating cardiac ANS innervation. ${ }^{123}$ I-MIBG planar and SPECT of the studies were performed at $20 \mathrm{~min}$ (early phase) and 3h (late phase) after intravenous injection of $111 \mathrm{MBq}{ }^{123} \mathrm{I}-\mathrm{MIBG}$. Following scatter correction, a region of interest (ROI) was set over the heart and rectangular ROI on the upper third of the mediastinum. Planar images were processed to determine the heart $(\mathrm{H})$ to mediastinum (M) ratio (H/M). The $\mathrm{H} / \mathrm{M}$ of average counts per pixel was calculated for the early and delayed images. ${ }^{123}$ I-MIBG SPECT study was performed using a $256 \times 256$ matrix, $4^{\circ}-6^{\circ}$ per step and $360^{\circ}$ rotation. Low-energy high-resolution (LEHR) collimators were used as previously reported [4]. The energy was centered on $159 \mathrm{keV}$ with a $20 \%$ window. The radiation dose of one SPECT equals to that of one gastric fluoscopy.

The Japanese (Age: $55 \pm 20$ ) average of $\mathrm{H} / \mathrm{M}$ in the early image were $2.2 \pm 0.2$, and $2.3 \pm 0.2$ for the delayed image low energy type collimeters were used [5].

\section{CASE REPORTS}

Case 1 was a 52-year-old male residential construction foreman, who had been diagnosed with acute schizophrenia-like psychotic disorder (ICD10 F23.2). He had been worked for over 20 years. He suffered from paranoia due to suddenly change residential design. There was no symptom of visual hallucinations, or Parkinsonism. Mini Mental State Exam (MMSE) scores were normal. He was diagnosed with adult ADHD (ICD $10 \mathrm{~F}$ 90.0). MIBG scintigraphy was performed 3 weeks after administration of bronanserin $8 \mathrm{mg} /$ day was stopped. MIBG scintigraphy is shown (Figure 1). The early and late $\mathrm{H} / \mathrm{M}$ ratios were 1.22 and 1.07 , respectively. Sudderth and Kandel score [6] was 10 (cut-off $>8$ ) and Hallowell and Ratey score [7] was 19 (cut-off $>15$ ).

Case 2 was a 52-year-old male civil servant who was diagnosed with adjustment disorder (ICD 10 F 43.2). He was required to play a different role due to the community integration. He was afraid of detailed change of his work and felt depressed. There was no symptom of visual hallucinations, or Parkinsonism. Mini Mental State Exam (MMSE) scores were normal. He has been also diagnosed with adult ADHD (ICD $10 \mathrm{~F}$ 90.0) MIBG scintigraphy is shown (Figure 2). The early and late H/M were 1.98 and 2.08, respectively. Sudderth and Kandel [6] score was 10 (cut-off $>8$ ) and Hallowell and Ratey [7] score was 17 (cut-off $>15$ ).

\section{DISCUSSION}

The MIBG uptake may vary depending on gender or age [8]. MIBG scintigraphy supports the view that imaging of sympathetic innervations may provide a sensitive, specific means to diagnose dementia with Lewy body disease (DLB) differentially from other forms of demen-

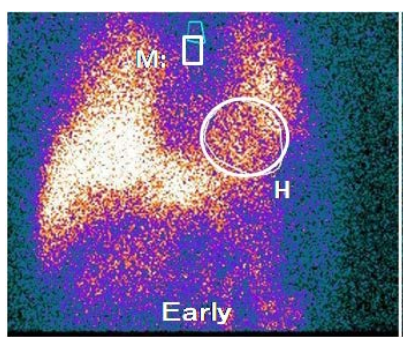

(a)

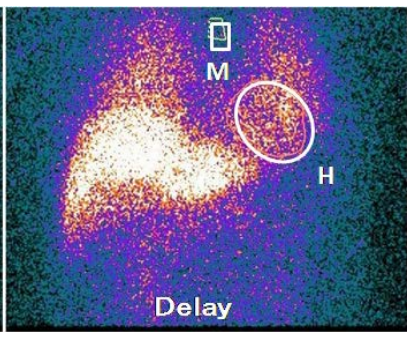

(b)
Figure 1. MIBG scintigraphy of case 1 is shown. Early planar image (a). H: 16910/1746 pix. M: 636/130pix. H/M: 1.98. Delay planar image (b). H: 14667/1756 pix. M: 525/130 pix. H/M: 2.08 .

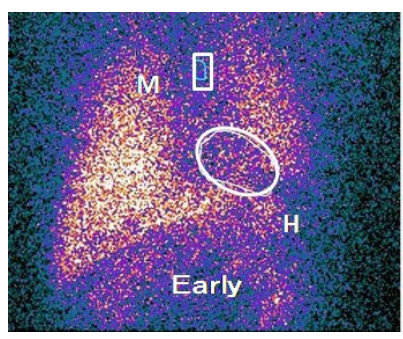

(a)

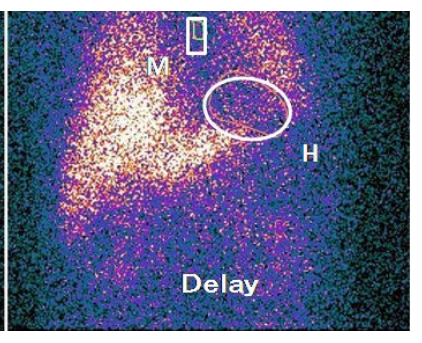

(b)
Figure 2. MIBG scintigraphy of case 2 is shown. Early planar image (a). H: 5608/1319 pix. M: 258/74 pix. H/M: 1.22. Delay planar image (b). H: 4671/1319 pix. M: 245/74 pix. H/M: 1.07.

tia, by detecting catecholaminergic denervation.

These two cases had past histories of their clinical evidence of diabetes mellitus or cardiovascular disease. Electrocardiography and chest radiography were performed before ${ }^{123}$ I-MIBG imaging to exclude myocardial disorders. Brain natriuretic peptide in the serum were normal and without autonomic nerve symptoms. And head MRI and electroencephalography were normal. These cases need to be paid attention to differential diagnose of incidental Lewy body disease (ILBD). This is an important issue needed for the follow-up to watch out of the latent stage of LBD.

Various tests are used for the identification of ADHD, but no standardized, diagnostic laboratory test has been established. Currently, diagnosis of ADHD involves behavioral descriptors that inevitably overlap with a range of other disorders [9]. Further, these interview and rating scales are often confounded by rater bias [10]. It is also known that adult ADHD is significantly commorbid with wide range of other 12-month disorders [11]. A high level of comorbidity between ADHD and psychiatric disorders has been reported [12]. Symptoms of these psychiatric disorders masked those of ADHD. Consequently adult ADHD is difficult to diagnose. In fact, these both patients were diagnosed with secondary ADHD although the ADHD had been predated adjustment disorder or brief psychotic disorder.

MIBG is an alkylguanidine that bears structural simi- 
larity to the neurotransmitter and catecholamine hormone-norepinephrine (NE).

Studies have demonstrated that MIBG is actively taken up in cells by the norepinephrine transporter (NET). NET terminates noradrenergic signaling by rapid re-uptake of neuronally released NE into presynaptic terminals. The NET exerts a finely regulated control over NE-mediated behavioral and physiological effects including mood, depression, feeding behavior, cognition, and regulation of blood pressure and heart rate [13].

It is known the states and process contribute to the increased cardiovascular morbidity on patients with psychiatric disorders. Psychological states and processes are known to profound affect the autonomic nervous system (ANS) control of the cardiovascular system [14]. It could be said that MIBG uptake might be an index of centralperipheral neural feedback and ANS-CNS integration.

Neurobiological and pharmacological research has suggested that regulation of central NE and NET is involved in several neuropsychiatric disorders in ADHD [15].

Up to $60 \%$ of children diagnosed with ADHD in early childhood continue to demonstrate notable ADHD symptoms as adults [16]. ADHD is one of the sustained psychiatric disorders for long periods of time. It is reported that stimulant-free children with ADHD demonstrated baseline parasympathetic dominance of the autonomic balance, relative to control subjects. Methylphenidate attempts to restore the normal autonomic balance in children with ADHD [17]. The presence of autonomic might be an important feature in making a clinical diagnosis of ADHD.

The presented cases might suggest that ADHD encompassed by CNS diseases might be influence ANS innervations.

\section{CONCLUSION}

The relation between psychiatric symptoms and sympathetic innervations is poorly understood. To the best of our knowledge, MIBG scintigraphy has not previously been used to investigate ADHD. These cases presented are male adult ADHD patients with preceded different psychiatric disorders. We here showed the possibility of a reduction in cardiac MIBG uptake in ADHD during remissions of psychiatric disorders. In patients with ADHD, the response to MIBG scintigraphy may vary among patients not only because of the duration of symptoms, but also because of the developmental state of the patient. Further research with additional subjects is clearly necessary.

\section{CONSENT}

Written informed consent was obtained from the patients for publica- tion of this case report.

\section{COMPETING INTERESTS}

Authors have no competing interests to declare that are relevant to the content of this submission.

\section{AUTHORS' CONTRIBUTIONS}

MH reviewed the literature and wrote the report. $\mathrm{MH}, \mathrm{TM}$, and JH took part in the scientific discussion and contributed to writing the case presentation.

All authors read and approved the final manuscript.

\section{REFERENCES}

[1] Murphy, K. and Barkley, R.A. (1993) Attention deficit hyperactive disorder adults: Comorbidities and adaptative impairments. Comprehensive Psychiatry, 37, 393-401. http://dx.doi.org/10.1016/S0010-440X(96)90022-X

[2] Bobb, A.J., Addington, A.M., Sidransky, E., Gornick, M.C., Lerch, J.P., Greenstein, D.K., Classen, L.S., Sharp, W.S., Inoff Germain, D.K., Classen, L.S., Sharp, W.S., Inoff-Germain, G., Wavrant De Vrieze, F., Across-Burgos, M., Straub, R.E., Hardy, J.A., Castellanos, F.X. and Rapport, J.L. (2005) Support for association between ADHD and two candidate genes: NET1 and DRD1. American Journal of Medical Genetics Part B: Neuropsychiatric Genetics, 134, 67-72. http://dx.doi.org/10.1002/ajmg.b.30142

[3] Hirakawa, M., Hakushi, S., Koike, Y., et al. (1995) A scintigraphical quantative analysis of peripheral vascular sympathetic function with meta-123I iodobenzylguanidine in neurological patients with autonomic failure. Journal of the Autonomic Nervous System, 53, 230-234. http://dx.doi.org/10.1016/0165-1838(95)00002-F

[4] Nakajima, K., Kusuoka, H., Nishimura, S., Yamashina, A. and Nishimura, T. (2007) Normal limits of ejection fraction and volumes determined bygated SPECT in clinically normal patients without cardiac events: A study based on the J-ACCESS database. European Journal of Nuclear Medicine and Molecular Imaging, 34, 1088-1096. http://dx.doi.org/10.1007/s00259-006-0321-1

[5] Matsuo, S., Nakajima, K., Yamashita, S., Sakata, K., Momose, M., Hashimoto, J., Kumita, S., Kawano, M. and Koichi, O. (2009) Characterization of Japanese standards for myocardial sympathetic and metabolic imaging in comparison with perfusion imaging. Annals of Nuclear Medicine, 23, 517-522. http://dx.doi.org/10.1007/s12149-009-0269-x

[6] Sudderth, D. and Kandel, J. (1997) Adult ADD: The complete hand book. Prima Publishing, Roseville.

[7] Peterson, T. (2000) Colleges for students with learning disabilities or ADD. In: Resnick, R.A., Ed., Clinicians' Guide to Attention Deficit Hyperactivity Disorder in Adults, American Psychological Association, Washington DC.

[8] Tsuchimoti, S., Tamaki, N., Tadamura, E., Kawamoto, T. and Kinoshita, M. (1995) Detection of denervated but 
viable myocardial adrenergic neuronal function evaluated by iodine-123-MIBG imageing. Journal of Nuclear Medicine, 36, 969-974.

[9] Nigg, J.T. (2005) Neuropsychologic theory and findings in attention-deficit-hyperactivity disorder: The state of the field and salient challenges for the coming decade. Biological Psychiatry, 57, 1424-1435. http://dx.doi.org/10.1016/j.biopsych.2004.11.011

[10] Monastra, V.J., Lubar, J.F. and Linden, M. (2001) The development of a quantative electroencephalographic scanning process for attention deficit-hyperactivity disorder: Reliability and validity studies. Neuropsychology, 15, 136-144. http://dx.doi.org/10.1037/0894-4105.15.1.136

[11] Kessler, R.C., Adler, L., Barkley, R., Biederman, J.C., Conners, K., Demler, O., Faraone, S.V., Greenhill, L.L., Howes, M.J., Secnik, K., Spencer, T., Ustun, B., Walters, E.E. and Zaslavsky, A.M. (2006) The prevalence and correlates of adult ADHD in the United States: Results from the National Comorbidity Survey Replication. American Journal of Psychiatry, 163, 716-723. http://dx.doi.org/10.1176/appi.ajp.163.4.716

[12] Ghanizadeh, A., Mommadi, M.R. and Moini, R. (2008) Comorbidity of psychiatric disorders and parental psychiatric disorders in a sample of iranian children with ADHD. Journal of Attention Disorders, 12, 149-155. http://dx.doi.org/10.1177/1087054708314601
[13] Bonisch, H. and Bruss, M. (2006) The norepinephrine transporter in physiology and disease. Handbook of Experimental Pharmacology, 175, 485-524. http://dx.doi.org/10.1007/3-540-29784-7_20

[14] Kim, C.K., McGorray, S.P., Bartholomew, B.A., Marsh, M., Dicken, T. and Wassertheil-Smoller, S. (2005) Depressive Symptoms and heart rate variability in post menopausal women. Archives of Internal Medicine, 165, 12391244. http://dx.doi.org/10.1001/archinte.165.11.1239

[15] Cho, S.C., Kim, J.W., Kim, B.N., Hwang, J.W., Park, M., Kim, S.A., Cho, D.Y., Yoo, H.J., Chung, U.S., Son, J.W. and Park, T.W. (2008) No evidence of an association between norepinephrine transporter gene polymorphisms and attention deficit hyperactivity disorder: A familybacsed and case-control association study in a Korean sample. Neuropsychology, 57, 131-138.

[16] Valdizán, J.R. and Izaguerri-Gracia, A.C. (2009) Attention deficit hyperactivity disorder in adults. Revista de Neurologia, 48, 95-99.

[17] Negrao, B.L., Bipath, P., Van der westhuizen, D. and Viljoen, M. (2011) Autonomic correlates at rest and during evoked attention in children with attention-deficit/ hyperactivity disorder and effects of methylphenidate. Neuropsychobiology, 63, 82-91. http://dx.doi.org/10.1159/000317548 